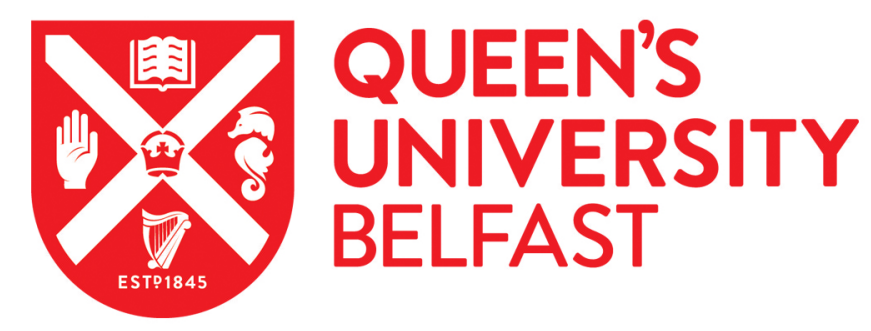

\title{
Modelling fresh properties of self-compacting concrete using Neural network technique
}

Sonebi, M., Grünewald, S., Cevik, A., \& Walraven, J. (2016). Modelling fresh properties of self-compacting concrete using Neural network technique. Computers and Concrete, 18(4), 903-921.

https://doi.org/10.12989/cac.2016.18.4.903

\section{Published in:}

Computers and Concrete

Document Version:

Peer reviewed version

Queen's University Belfast - Research Portal:

Link to publication record in Queen's University Belfast Research Portal

Publisher rights

(C)2016 Techno-Press.

This work is made available online in accordance with the publisher's policies. Please refer to any applicable terms of use of the publisher.

\section{General rights}

Copyright for the publications made accessible via the Queen's University Belfast Research Portal is retained by the author(s) and / or other copyright owners and it is a condition of accessing these publications that users recognise and abide by the legal requirements associated with these rights.

Take down policy

The Research Portal is Queen's institutional repository that provides access to Queen's research output. Every effort has been made to ensure that content in the Research Portal does not infringe any person's rights, or applicable UK laws. If you discover content in the Research Portal that you believe breaches copyright or violates any law, please contact openaccess@qub.ac.uk. 


\title{
Modelling fresh properties of self-compacting concrete using neural network technique
}

\author{
Mohammed Sonebi ${ }^{* 1}$, Steffen Grünewald ${ }^{2,3}$, Abdulkadir Cevik ${ }^{4}$, Joost Walraven ${ }^{2}$ \\ ${ }^{1}$ School of Planning, Architecture and Civil Engineering, Queen's University Belfast, Belfast, BT7 1NN, \\ Northern Ireland, UK \\ ${ }^{2}$ Faculty of Civil Engineering and Geosciences, Delft University of Technology, 2600 GA, Delft, The \\ Netherlands \\ ${ }^{3}$ Department of Civil Engineering, Ghent University, B9052, Ghent, Belgium \\ ${ }^{4}$ Department of Civil Engineering, University of Gaziantep, Turkey
}

(Received keepasblank , Revised keep asblank , Accepted keepasblank )

\begin{abstract}
The purpose of this paper is to investigate the feasibility of using artificial neural network programming for the prediction of the fresh properties of self-compacting concrete. The input parameters of the neural network were the mix composition influencing the fresh properties of self-compacting concrete namely, the cement content, the dosages of limestone powder and water, fine aggregate, coarse aggregate, and superplasticizer, and other parameter of time of testing $(5,30$ and 60 minutes after addition of water). The model is based on a multilayer feed forward neural network. The details of the proposed ANN with its architecture, training and validation are presented in this paper. Six outputs of the ANN models related to the fresh properties were the slump flow, $T_{50}, T_{60}$, V-funnel flow time, Orimet flow time, and blocking ratio (L-box). The effectiveness of the trained ANN is evaluated by comparing its responses with the experimental data that were used in the training process. The dosage of water was varied from 188 to $208 \mathrm{~L}^{3}$, the dosage of SP from 3.8 to $5.8 \mathrm{~kg} / \mathrm{m}^{3}$, and the volume of coarse aggregates from 220 to $360 \mathrm{Lm}^{3}\left(587\right.$ to $\left.961 \mathrm{~kg} / \mathrm{m}^{3}\right)$. In total twenty mixes were used to measure the fresh properties with different mix compositions. ANN performed well and provided very good correlation coefficients $\left(\mathrm{R}^{2}\right)$ above 0.957 for slump flow, $\mathrm{T}_{50}$, V-funnel flow time, Orimet flow time, and L-box blocking ratio. The predicting results for $\mathrm{T}_{60}$ was slightly lower $\left(\mathrm{R}^{2}=0.823\right)$. With the calculated models these properties of new mixes within the practical range of the input variables used in the training can be predicted with an absolute error for slump flow, $\mathrm{T}_{50}, \mathrm{~T}_{60}$, V-funnel flow time, Orimet flow time, and L-box ratio of 3.3\%,13\%,16\%,14\%,15\%, and 22\%, respectively. The results show that the ANN model can predict accurately the fresh properties of SCC.
\end{abstract}

Keywords: artificial neural network; blocking ratio of L-box test; orimet; prediction model; slump flow; V-funnel

\section{Introduction}

The use of self-compacting concrete (SCC) facilitates the placing of concrete by eliminating the need for compaction by vibration. Due to the highly flowable nature of SCC, care is required to ensure excellent filling ability and passing ability and adequate stability. It is essential to

\footnotetext{
${ }^{* 1}$ Corresponding author, Dr , E-mail: m.sonebi@qub.ac.uk
} 
reduce the coarse aggregate volume compared with conventional concrete, and to increase the volume of fine aggregate and the paste volume to enhance the filling ability. The incorporation of continuously graded cement and fillers also can reduce inter-particle friction. It is important to note that the selection of proper combinations of powders should take into account the effect of the adsorption of water and admixtures on the workability loss and the rise of temperature, as well as the durability and the development of properties in the hardened state (DeSchutter et al. 2007, Sonebi et al., 2003, Sonebi et al. 2009a). The inter-particle friction between the various solids (coarse aggregate, sand, and powder materials) affects the filling ability. Such solid-to-solid friction increases the internal resistance to flow, thus limiting the filling ability and speed of flow of the fresh concrete. The extent of inter-particle friction increases when the concrete passes through restricted spaces because of the locally greater probability of collisions between the particles of the various solids in the mix. This increases the rate of shear, thus resulting in greater shear stresses at a given capacity of the flow. The use of SP can disperse cement grains and reduce inter-particle friction and enables the reduction in water content while maintaining the required level of flowability (Sonebi 2004, Hossain et al., 2012).

The stability of self-compacting concrete can be enhanced by incorporating fine materials such as for example limestone powder, ground granulated blast slag (GGBS), fly ash, microsilica fume, metakaolin, etc. (Sonebi 2004, Khatib 2008, Sonebi et al. 2009a, Hossain et al. 2012). The use of such powders can enhance the grain-size distribution and the particle packing, thus ensuring greater cohesiveness (Khatib 2008). Another approach to enhance the stability of selfcompacting concrete is to incorporate a viscosity-modifying agent (VMA) along with a SP to ensure high fluidity and deformability, and adequate stability (Lachemi et al. 2004, Sonebi 2004, Khatib 2008, Leeman et al., 2007).

The filling ability of SCC (unconfined flowability) can be described by the ability of the concrete to flow into and to fill all spaces of the formwork under its own weight. Slump flow, T50, T60, V-funnel, Orimet and the blocking ratio were used to measure both filling ability and passing ability. T50 and the flow times of V-funnel and Orimet can be used to assess the viscosity (Sonebi 2004, Khatib 2008). The passing ability of SCC is the ability to flow through tight openings, such as spaces between reinforcing bars, under its own weight. If the concrete does not possess adequate passing ability, coarse aggregates will cause blockage between the reinforcing bars and resulting in a non-uniform structure. The L-box, U-box, and J-ring test methods were suitable to assess the passing ability through closely spaced reinforcing bars (Bartos et al. 2002, ACI 237R-07 2007).

Many researchers and engineers have reported the use of artificial neural network to predict the fresh properties of concrete such as high performance concrete, lightweight concrete, high performance grouts, recycling concrete, alkali silica reaction of concrete with nano-silica and indirect tensile strength of SCC (Yeh 2007, Mohebbi et al. 2011, Sonebi et. al 2011, Sonebi et al. 2009a, Duan et al. 2013, Tabatabaei et al. 2014, Mazloom et al. 2013).

Sonebi and Cevik used neurofuzzy (2009b) to predict the properties of fresh and hardened SCC containing Pulverised Fuel Ash (PFA). The proposed neurofuzzy models gave accurate predictions, as compared to experimental results, for all of the properties of fresh and hardened SCC considered in their study. In addition, they proposed genetic programming formulas for calculating fresh and hardened properties of SCC containing PFA. They concluded that fresh and hardened properties of SCC are sensitive to the variation of mix ingredients.

Artificial Neural Networks was used to model the slump values of fly ash and slag concrete based on its ingredients. The complex nonlinear relationship between concrete components and 
concrete slump can be modeled more accurately using ANN as compared to nonlinear regression models. In addition, it was reported that response trace plots generated from ANN models for numerical experiments can be used conveniently to review the effects of mix proportions on concrete properties (Yeh 2007).

Prasad et al. (2009) used ANN to predict slump flow and strength of SCC containing high volume fly ash. They reported that the performance of ANN in predicting the slump flow is satisfactory but not as accurate as in predicting the compressive strength of SCC.

Tabatabaei et al. (2014) reported that analysis of the ANN model determines the optimal percentage of additives, which has a strong influence on the rheological properties of fresh self compacting cement paste. Their proposed ANN models showed that metakaolin and silica fume affected the rheological properties in the same manner. Additionally, the ANN model introduced the optimal percentage of metakaolin, silica fume, calcium carbonate and limestone as 15, 15, 20 and $20 \%$ by cement weight, respectively.

ANN modeling is a nonlinear statistical technique used to solve problems that are not amenable to conventional methods. In addition, to develop an effective ANN model, the network should be able to accurately predict the output when trained with a set of inputs within the practical range of the training data. The most common feed-forward ANNs are used where information is processed in one direction - from input to output - and the neurons are ordered in layers. They consist of an input layer, an output layer, and a number of hidden (intermediate) layers. An input layer is where data are presented to the neural network, whereas the output layer contains the response of the network. ANNs are powerful modeling techniques based on a statistical approach. These neural network modeling require a significant amount of data and powerful computing resources in order to work. Hence, they are suitable for simulations of correlations which are hard to describe by physical models. The model ANN can also run conveniently on almost any computer once it is created.

\section{Research significance}

The complexity of the fresh properties of SCC resulted in attempts mostly empirical in nature. The optimization of SCC often necessitates carrying out several trial batches to achieve adequate balance between filling ability, flowabilility, and passing ability. Only recently, ANN attracted a growing interest in engineering applications including the modeling of concrete properties and cement-based materials. In this paper, the feasibility of using artificial neural networks is studied to create such models that can be used to predict the flowability, filling ability, passing ability with the time of testing. ANN can assist in designing SCC mixes without the need for a large number of trial mixes.

\section{Experimental program}

\subsection{Materials}

The concrete mixes investigated in this study were prepared with CEM II-42.5 R cement in accordance with conform to EN 197-1, and limestone powder (LSP). LSP, produced from very high purity carboniferous limestone $\left(\mathrm{CaCO}_{3}=98 \%\right)$ was used. The chemical properties of cement and LSP are presented in Table 1. The specific densities of the limestone powder and cement were 2.70 and 3.08 $\mathrm{kg} / \mathrm{dm}^{3}$, respectively. The grading curves of cement and LSP are given in Figure 1. The mean particle 
size of LSP $\left(\mathrm{d}_{50} \%\right)$ was $4.5 \mu \mathrm{m}$ and $22 \%$ of particles were smaller than $2 \mu \mathrm{m}$. LSP was finer than the cement.

Continuously graded crushed granite aggregates $4 / 8 \mathrm{~mm}$ and $8 / 16 \mathrm{~mm}$ and marine sand from Denmark were used. The specific densities of the coarse aggregates $4 / 8 \mathrm{~mm}$ and $8 / 16 \mathrm{~mm}$ and sand were $2.67,2.67$ and 2.65 , and their absorption were $0.87 \%, 0.72 \%$ and $0.30 \%$, respectively. The grading sizes of the coarse aggregates and the sand are given in Fig. 1. A polycarboxylic-based SP was used, which had a solid content and specific density of $30 \%$ and 1.05 , respectively.

Table 1 Chemical and physical properties of cementitious materials

\begin{tabular}{|c|c|c|}
\hline Property & Limestone powder & CEM II \\
\hline $\mathrm{SiO}_{2}, \%$ & 0.8 & 18.5 \\
$\mathrm{Al}_{2} \mathrm{O}_{3}, \%$ & -- & 5.0 \\
$\mathrm{Fe}_{2} \mathrm{O}_{3}, \%$ & 0.1 & 2.9 \\
$\mathrm{CaO}, \%$ & -- & 62.0 \\
$\mathrm{MgO}, \%$ & -- & 1.2 \\
$\mathrm{SO}_{3}, \%$ & -- & 3.6 \\
$\mathrm{Na}_{2} \mathrm{O}$ eq. $\%$ & -- & 0.39 \\
$\mathrm{LOI} \%$ & -- & 0.65 \\
$\mathrm{CaCO}_{3}, \%$ & 98.0 & -- \\
\hline Relative Density $\left(\mathrm{kg} / \mathrm{dm}^{3}\right)$ & 2.70 & 3.08 \\
Bulk Density $(\mathrm{Packed})$ & 1200 & -- \\
Blaine $\left(\mathrm{m}^{2} / \mathrm{kg}\right)$ & -- & 469 \\
\hline
\end{tabular}

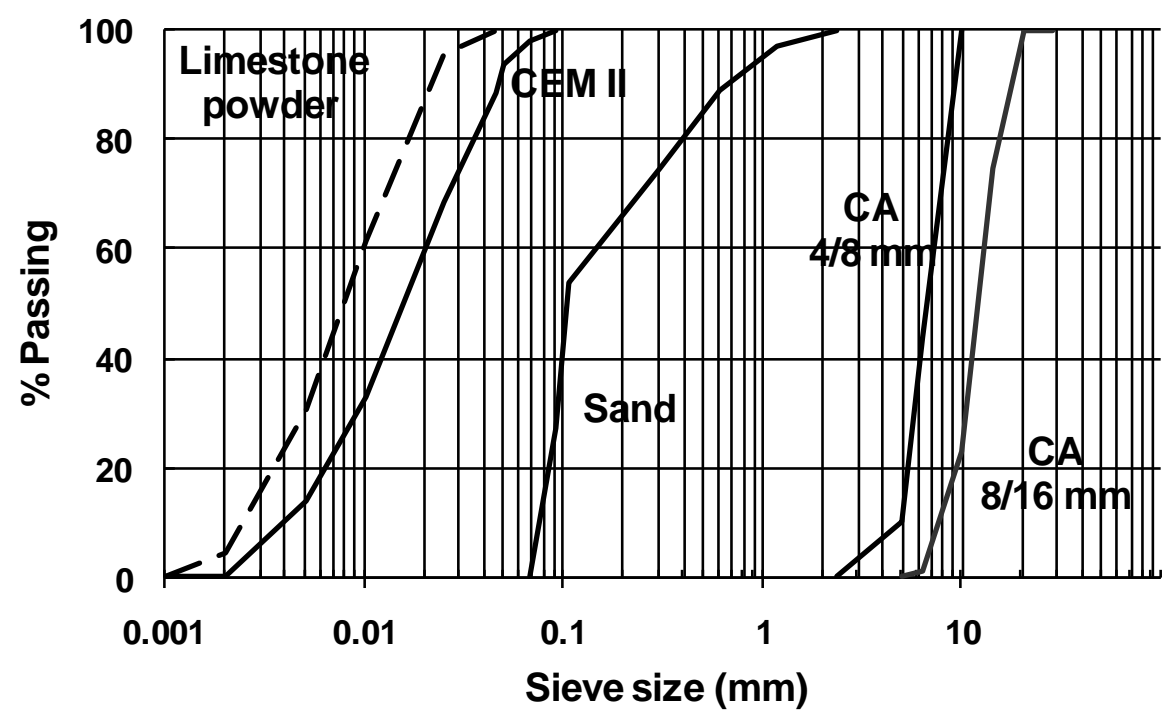

Fig. 1 Particle size distribution of coarse aggregates, sand, cement and limestone powder 


\subsection{Experimental plan}

The key parameters that can have a significant influence on mix characteristics of SCC were selected for evaluating their effect on the flowability, filling ability and passing properties. In total, 20 mixes were tested. The reference SCC mix having a good filling ability, passing ability and a good stability was made with $198 \mathrm{~L} / \mathrm{m}^{3}$ of water, $133 \mathrm{~kg} / \mathrm{m}^{3}$ of limestone powder, $470 \mathrm{~kg} / \mathrm{m}^{3}$ of cement, $291 \mathrm{~L} / \mathrm{m}^{3}$ of volume of coarse aggregate and $4.75 \mathrm{~kg} / \mathrm{m}^{3}$ of SP. For all mixes, when the dosages of water and SP were varied, the ratio by volume of cement to limestone powder was the same (3.01) and the ratio between the coarse aggregates fractions $(4 / 8 \mathrm{~mm}$ and $8 / 16 \mathrm{~mm}$ was kept constant at 0.43 ). The volume of sand was adjusted to compensate for the increase or decrease of the coarse aggregates. The mixes were made with water content in the range of 188 to $208 \mathrm{~L} / \mathrm{m}^{3}$, dosages of SP of 3.8 to $5.8 \mathrm{~kg} / \mathrm{m}^{3}$, and the volume of coarse aggregate of 220 to $361 \mathrm{~L} / \mathrm{m}^{3}$. The measurement of fresh properties are the slump flow, $\mathrm{T}_{50}, \mathrm{~T}_{60}$, the V-funnel and Orimet flow times and the blocking ratio 5, 30 and 60 minutes after adding the first water. The variation of the parameters was chosen in order to obtain a wide range of characteristics in the fresh state.

\subsection{Test methods}

All concrete mixes were prepared in 40 litres batches in a rotating planetary mixer with a $120 \mathrm{~L}$ capacity. The batching sequence consisted of homogenizing the powders, the sand and the coarse aggregates for 60 seconds, then adding most of the water into the mixer (except $50 \mathrm{ml}$ ) and continuing to mix for another minute. After adding SP and the remaining water, the concrete was mixed for three minutes.

Slump flow, $\mathrm{T}_{50}, \mathrm{~T}_{60}, \mathrm{~V}$-funnel, Orimet, and L-box were used to test the filling ability (workability and deformability), and passing ability of SCC in accordance with EFNARC guideline (2002). $\mathrm{T}_{50}$ and $\mathrm{T}_{60}$ are the times, which the concrete requires to reach $500 \mathrm{~mm}$ and 600 $\mathrm{mm}$ of slump flow and they are a good indication of the viscosity of concrete. The ability of aggregate particles and mortar to change their flow paths and spread through a restricted area without blockage was evaluated using V-funnel and Orimet (Fig. 2). The Orimet is the same as developed by Bartos et al. (2002) where the flow of concrete is noted as the time between the opening of the outlet and the time when the light becomes visible from the top. The orifices of Vfunnel and Orimet were a square $(75 \times 75 \mathrm{~mm})$ and circular (diameter $=80 \mathrm{~mm}$ ), respectively. The basic Orimet is provided with an orifice, which reduces the internal diameter from $120 \mathrm{~mm}$ within the casting pipe to $80 \mathrm{~mm}$ at the end of the orifice, a sample of at least 7.5 litres of fresh concrete mix is required. The L-box used is shown in Fig. 2. It is possible to measure filling ability and passing ability with the L-box. The vertical part of the box $(100 \times 200 \times 600 \mathrm{~mm})$ is filled with 12.7 litres of concrete, which is left to rest for one minute in order to allow any segregation to occur. After that, the gate is opened and the concrete flows out of the vertical part into the horizontal part $(150 \times 200 \times 700 \mathrm{~mm})$ through the reinforcement bars. The gap between the reinforcement bars was $34 \mathrm{~mm}$. Three rib bars were used in the L-box. The height $\mathrm{H}_{1}$ and $\mathrm{H}_{2}$ of concrete were measured and used to determine the L-box blocking ratio $\left(\mathrm{h}_{2} / \mathrm{h}_{1}\right.$-ratio, Figure 2). All tests slump flow, V-funnel, Orimet and L-box were carried out at $5 \mathrm{~min}, 30 \mathrm{~min}$ and $60 \mathrm{~min}$. 


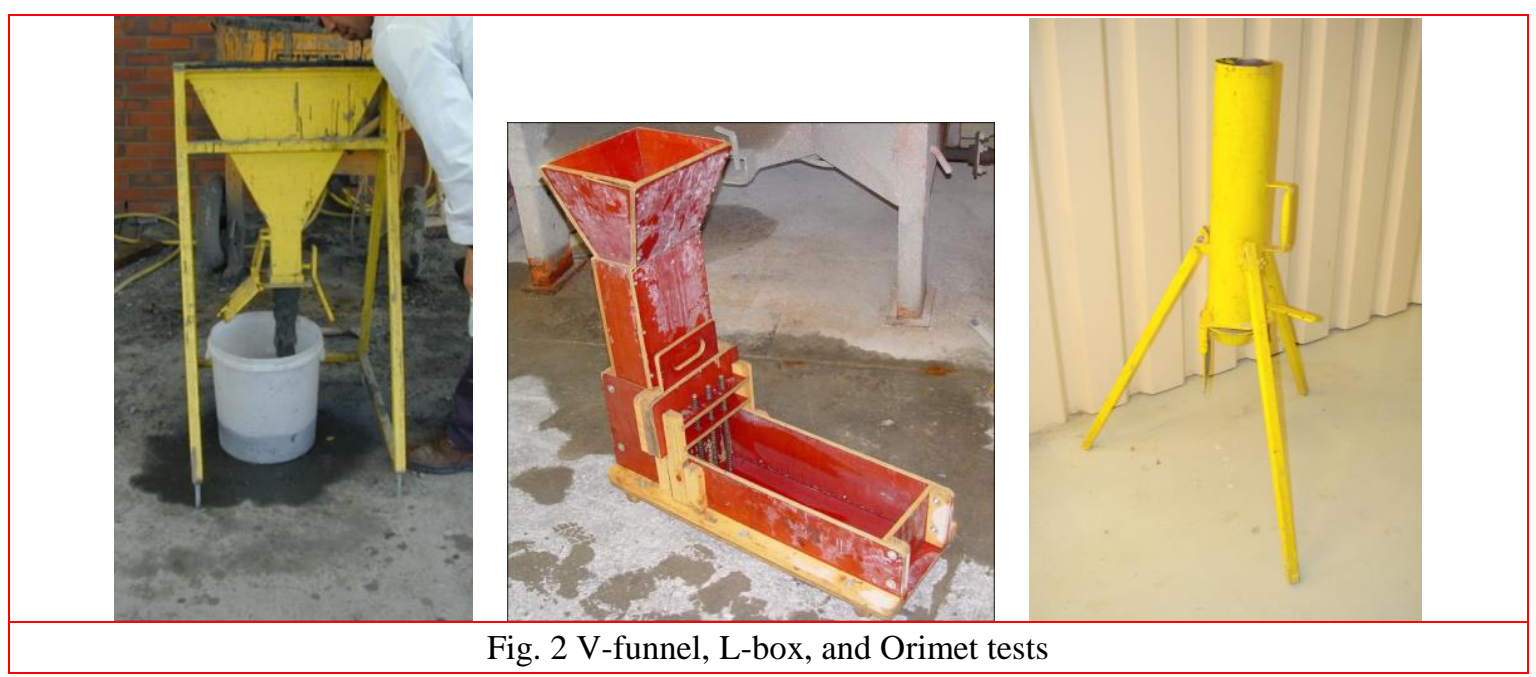

\section{Test results and discussion}

The mix proportions and the results of fresh properties of all mixes prepared in this study are summarized in Tables 2 and 3, respectively.

Table 2 Mix proportions of tested mixes

\begin{tabular}{|c|c|c|c|c|c|c|c|c|}
\hline Mix & $\begin{array}{c}\text { Cement } \\
\left(\mathrm{kg} / \mathrm{m}^{3}\right)\end{array}$ & $\begin{array}{c}\text { LSP } \\
\left(\mathrm{kg} / \mathrm{m}^{3}\right)\end{array}$ & $\begin{array}{c}\text { Water } \\
\left(\mathrm{kg} / \mathrm{m}^{3}\right)\end{array}$ & $\begin{array}{c}\text { SP } \\
\left(\mathrm{kg} / \mathrm{m}^{3}\right)\end{array}$ & $\begin{array}{c}\text { CA. 4/8mm } \\
\left(\mathrm{kg} / \mathrm{m}^{3}\right)\end{array}$ & $\begin{array}{c}\text { CA. 8/16mm } \\
\left(\mathrm{kg} / \mathrm{m}^{3}\right)\end{array}$ & $\begin{array}{c}\text { Sand } \\
\left(\mathrm{kg} / \mathrm{m}^{3}\right)\end{array}$ & W/B \\
\hline 1 & 448 & 127 & 208 & 3.8 & 290 & 673 & 604 & 0.37 \\
2 & 444 & 126 & 208 & 5.8 & 178 & 412 & 975 & 0.37 \\
3 & 495 & 140 & 188 & 3.8 & 290 & 673 & 604 & 0.30 \\
4 & 491 & 139 & 188 & 5.8 & 290 & 673 & 604 & 0.31 \\
5 & 495 & 140 & 188 & 3.8 & 178 & 412 & 975 & 0.30 \\
6 & 491 & 139 & 188 & 5.8 & 178 & 412 & 975 & 0.31 \\
7 & 448 & 127 & 208 & 3.8 & 178 & 412 & 975 & 0.37 \\
8 & 444 & 126 & 208 & 5.8 & 290 & 673 & 604 & 0.37 \\
9 & 470 & 133 & 198 & 4.8 & 234 & 543 & 789 & 0.34 \\
10 & 470 & 133 & 198 & 4.8 & 234 & 543 & 789 & 0.34 \\
11 & 470 & 133 & 198 & 4.8 & 234 & 543 & 789 & 0.34 \\
12 & 470 & 133 & 198 & 4.8 & 234 & 543 & 789 & 0.34 \\
13 & 470 & 133 & 198 & 4.8 & 234 & 543 & 789 & 0.34 \\
14 & 470 & 133 & 198 & 4.8 & 234 & 543 & 789 & 0.34 \\
15 & 509 & 144 & 181 & 4.8 & 234 & 543 & 789 & 0.28 \\
16 & 430 & 122 & 215 & 4.8 & 234 & 543 & 789 & 0.40 \\
17 & 473 & 134 & 198 & 3.1 & 234 & 543 & 789 & 0.33 \\
18 & 466 & 132 & 198 & 6.4 & 234 & 543 & 789 & 0.34 \\
19 & 470 & 133 & 198 & 4.8 & 328 & 762 & 478 & 0.34 \\
20 & 470 & 133 & 198 & 4.8 & 139 & 323 & 1100 & 0.34 \\
\hline
\end{tabular}

LSP: Limestone powder; W/B : water-to-binder ratio 
Table 3 Properties of fresh properties of concretes

\begin{tabular}{|c|c|c|c|c|c|c|c|c|c|c|c|c|c|c|}
\hline Mix & $\begin{array}{l}\text { Slump } \\
\text { Flow } \\
5 \text { min }\end{array}$ & $\begin{array}{l}\text { Slump } \\
\text { Flow } \\
30 \mathrm{~min}\end{array}$ & $\begin{array}{l}\text { Slump } \\
\text { Flow } \\
60 \mathrm{~min}\end{array}$ & $\begin{array}{c}\mathrm{T}_{50} \\
\text { at } 5 \mathrm{~min}\end{array}$ & $\begin{array}{c}\mathrm{T}_{60} \\
\text { at } 5 \mathrm{~min}\end{array}$ & $\begin{array}{c}\mathrm{V}- \\
\text { Funnel } \\
5 \mathrm{~min}\end{array}$ & $\begin{array}{c}\text { V- } \\
\text { Funnel } \\
30 \text { min }\end{array}$ & $\begin{array}{c}\text { V- } \\
\text { Funnel } \\
60 \text { min }\end{array}$ & $\begin{array}{l}\text { Orimet } \\
5 \mathrm{~min}\end{array}$ & $\begin{array}{l}\text { Orimet } \\
30 \mathrm{~min}\end{array}$ & $\begin{array}{l}\text { Orimet } \\
60 \mathrm{~min}\end{array}$ & $\begin{array}{l}\text { L-box } \\
5 \text { min }\end{array}$ & $\begin{array}{l}\text { L-box } \\
30 \mathrm{~min}\end{array}$ & $\begin{array}{l}\text { L-box } \\
60 \text { min }\end{array}$ \\
\hline & $(\mathrm{mm})$ & $(\mathrm{mm})$ & $(\mathrm{mm}$ & (s) & (s) & (s) & (s) & (s) & (s) & (s) & (s) & & & \\
\hline 1 & 755 & 700 & 578 & 1.86 & 3.78 & 20.0 & 20.9 & 38.1 & 15.6 & 30.5 & 47.0 & 0.98 & 0.52 & 0.03 \\
\hline 2 & 878 & 820 & 765 & 0.9 & 2.03 & 4.1 & 4.9 & 6.7 & 2.1 & 2.5 & 3.3 & 1.00 & 1.00 & 1.00 \\
\hline 3 & 608 & 375 & 315 & 3.55 & 9.53 & 22.8 & 66.7 & --- & -- & -- & --- & 0.42 & 0.00 & 0.00 \\
\hline 4 & 775 & 630 & 565 & 2.15 & 4.22 & 47.4 & 85.5 & 101.0 & 47.1 & 67.3 & 138.0 & 0.89 & 0.53 & 0.00 \\
\hline 5 & 515 & 335 & 273 & 4.4 & --- & 11.9 & 29.0 & --- & 7.9 & 11.8 & --- & 0.26 & 0.00 & 0.00 \\
\hline 6 & 688 & 555 & 490 & 3.45 & 8.22 & 8.9 & 9.6 & 14.3 & 4.8 & 6.1 & 9.2 & 0.88 & 0.73 & 0.49 \\
\hline 7 & 808 & 620 & 535 & 0.86 & 1.93 & 4.6 & 5.9 & 7.6 & 2.3 & 3.3 & 5.1 & 0.98 & 0.79 & 0.54 \\
\hline 8 & 923 & 720 & 735 & 1.21 & 1.70 & 11.8 & 16.1 & 16.2 & 12.3 & 16.9 & 22.1 & 0.89 & 0.70 & 0.64 \\
\hline 9 & 788 & 660 & 555 & 1.43 & 2.69 & 6.9 & 11.3 & 22.8 & 3.5 & 7.2 & 10.3 & 1.00 & 0.86 & 0.52 \\
\hline 10 & 800 & 675 & 605 & 1.30 & 3.00 & 6.5 & 11.5 & 19.3 & 3.6 & 6.7 & 9.9 & 0.99 & 0.97 & 0.70 \\
\hline 11 & 793 & 655 & 623 & 1.27 & 2.59 & 6.8 & 9.1 & 15.1 & 3.3 & 5.2 & 21.9 & 0.98 & 0.86 & 0.76 \\
\hline 12 & 818 & 710 & 640 & 1.55 & 2.50 & 5.7 & 9.0 & 12.1 & 2.9 & 5.6 & 5.5 & 1.00 & 0.97 & 0.76 \\
\hline 13 & 778 & 705 & 675 & 0.80 & 1.99 & 5.8 & 8.1 & 13.5 & 3.1 & 4.7 & 19.6 & 0.98 & 0.83 & 0.77 \\
\hline 14 & 808 & 685 & 638 & 1.49 & 3.00 & 5.3 & 7.7 & 11.2 & 3.1 & 4.6 & 25.8 & 0.96 & 0.90 & 0.75 \\
\hline 15 & 525 & 350 & 283 & 6.74 & --- & 18.3 & 70.5 & --- & 13.3 & 22.4 & --- & 0.35 & 0.00 & 0.00 \\
\hline 16 & 945 & 810 & 793 & 1.03 & 1.84 & 3.0 & 4.3 & 7.9 & 1.6 & 2.8 & 18.7 & 1.00 & 1.00 & 0.97 \\
\hline 17 & 655 & 470 & 385 & 1.67 & 4.31 & 7.0 & 9.1 & --- & 3.4 & 6.8 & 11.8 & 0.72 & 0.24 & 0.00 \\
\hline 18 & 845 & 830 & 758 & 1.24 & 2.06 & 5.1 & 7.1 & 10.6 & 2.2 & 3.6 & 25.6 & 0.93 & 1.00 & 0.96 \\
\hline 19 & 718 & 625 & 520 & 3.80 & 6.63 & 18.0 & 24.6 & 27.2 & 26.1 & 27.9 & 45.3 & 0.62 & 0.25 & 0.04 \\
\hline 20 & 688 & 565 & 498 & 2.62 & 5.94 & 7.2 & 7.7 & 11.3 & 3.7 & 5.1 & 8.01 & 0.87 & 0.70 & 0.41 \\
\hline
\end{tabular}




\subsection{Basıc princıples and development of the neural networks}

The general scheme of the model of ANN for the prediction of the fresh properties is given in Fig. 3. The input parameters of the neural network are compositions of self-compacting concrete which are commonly applied components, namely dosage of water, cement content, limestone powder content (LSP), sand content, coarse aggregate content, SP and time. The outputs of the neural network model comprised the fresh properties of SCC examined namely slump flow, $\mathrm{T}_{50}$, $\mathrm{T}_{60}, \mathrm{~V}$-funnel, Orimet and the L-box blocking ratio.

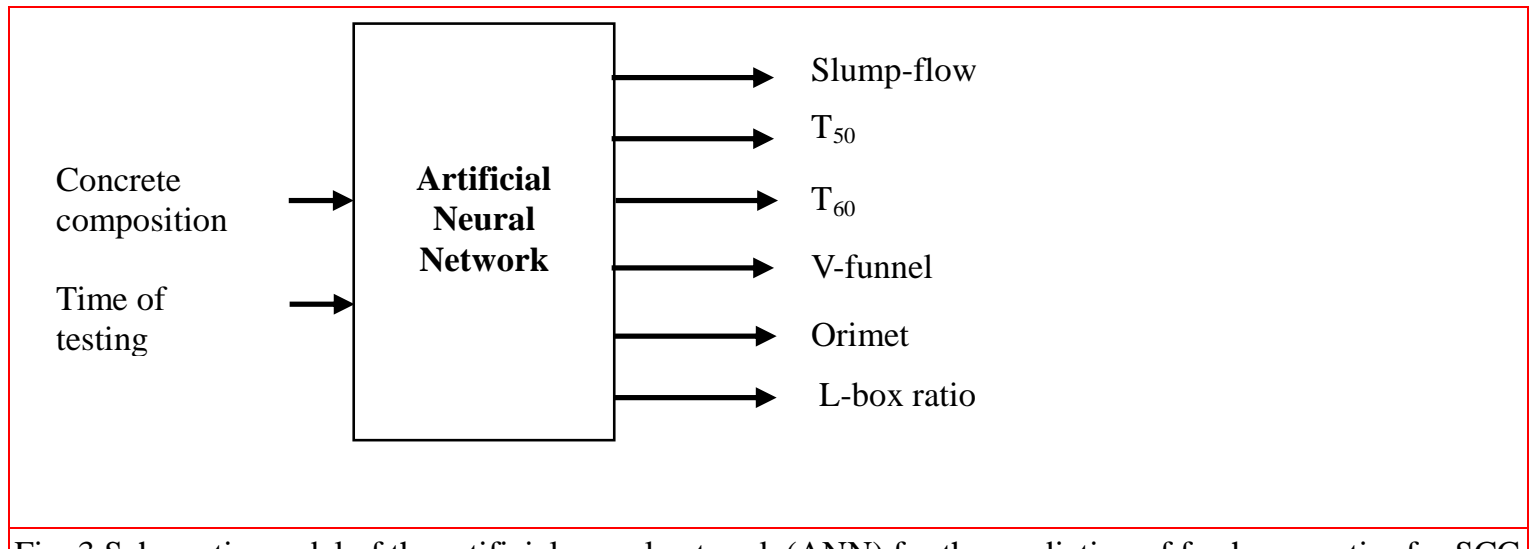

Fig. 3 Schematic model of the artificial neural network (ANN) for the prediction of fresh properties for SCC

An artificial neural network, in short, a neural network is an information processing system that mimics the biological system of the brain and hence, is a powerful computational tool capable of self-organizing, pattern recognition, and functional approximation. Neural networks are also nowadays used in engineering applications including the modeling of concrete properties, and cement-based materials.

Artificial neural network modeling is a nonlinear statistical technique used to solve problems that are not amenable to conventional methods. Although they had been successful in identifying complex nonlinear relationships and in modeling various applications, their effectiveness depends mainly on the quality of the database used for its training. In addition, in order to develop an effective ANN model, the network should be able to accurately predict the output when trained with a set of inputs within the practical range of the training data (Haykin 1999).

In this study the most common Feed-forward ANNs are used where information is processed in one direction -from input to output- and the neurons are ordered in layers. They consist of an input layer, an output layer, and a number of hidden (intermediate) layers. An input layer is where data is presented to the neural network, whereas the output layer contains the response of the network (Fig. 4).

In this study Matlab ANN toolbox is used for ANN applications. Various Back propagation Training Algorithms are used given in Table 1. Matlab ANN toolbox randomly assigns the initial weights for each run each time which considerably changes the performance of the trained ANN even all parameters and ANN architecture are kept constant. This leads to extra difficulties in the selection of optimal Network architecture and parameter settings. To overcome this difficulty a program has been developed in Matlab which handles the trial and error process automatically. 
The program tries various number of layers and neurons in the hidden layers both for first and second hidden layers for a constant epoch for several times and selects the best ANN architecture with the minimum MAPE (Mean Absolute \% Error) or RMSE (Root Mean Squared Error) of the testing set, as the training of the testing set is more critical. For instance an ANN architecture with 1 hidden layer with 7 nodes is tested 10 times and the best ANN is stored where in the second cycle the number of hidden nodes is increased up to 8 and the process is repeated. The best ANN for cycle 8 is compared with cycle 7 and the best one is stored as best NN. This process is repeated $\mathrm{N}$ times where $\mathrm{N}$ denotes the number of hidden nodes for the first hidden layer. This whole process is repeated for changing number of nodes in the second hidden layer. More over this selection process is performed for different back propagation training algorithms such as trainlm, trainscg and trainbfg given in Table 4 (Cevik 2006). The program begins with simplest ANN architecture i.e. ANN with 1 hidden node for the first and second hidden layers and ends up with optimal NN architecture as shown in Fig 4.

Table 4 Back propagation Training Algorithms used in NN training.

\begin{tabular}{|l|l|}
\hline $\begin{array}{l}\text { MATLAB } \\
\text { Function name }\end{array}$ & Algorithm \\
\hline \hline trainbfg & BFGS quasi-Newton back propagation \\
\hline traincgf & Fletcher-Powell conjugate gradient back propagation \\
\hline traincgp & Polak-Ribiere conjugate gradient back propagation \\
\hline traingd & Gradient descent back propagation \\
\hline traingda & Gradient descent with adaptive lr back propagation \\
\hline traingdx & Gradient descent w/momentum \& adaptive linear back propagation \\
\hline trainlm & Levenberg-Marquardt back propagation \\
\hline trainoss & One step secant back propagation \\
\hline trainrp & Resilient back propagation (Rprop) \\
\hline trainscg & Scaled conjugate gradient back propagation \\
\hline
\end{tabular}

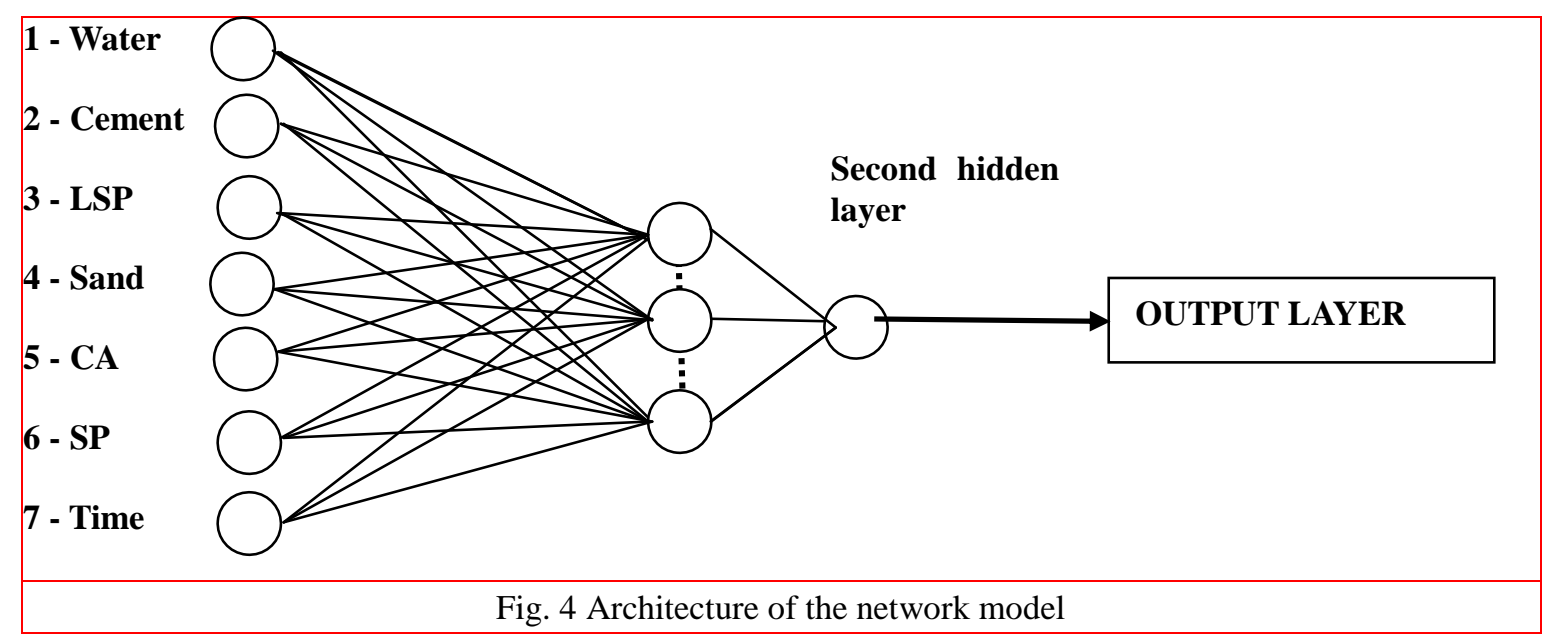


Without the hidden layer, only linear tasks are performed hence, ANN loses its advantage to present and compute complicated associations between patterns. Each hidden layer includes a number of neurons (processing units) partially of fully connected to neurons (synapses) in the adjacent layers, and no connection is permitted between neurons within the same layer. Each neuron in the hidden and output layers receives multiple inputs from neurons in the previous layer through connections with associated strengths (weights).

The weights are the coefficients of linear combinations plus biases. These weights represent the backbone of the ANN model whereby they determine the nature and strength of the influence between the interconnected neurons. Each neuron then performs a simple computation to calculate a net input (weighted sum) and to transform that net input into an output via an assigned transfer function to serve as an input to neurons in the subsequent layer or as a network output if the neuron is in the output layer as shown in Fig. 4.

The transfer function is generally non linear sigmoid. A 'sigmoid' function is an S-shaped "squashing function" which maps a real value, which may be arbitrarily large in magnitude, positive or negative to a real value, which lies within some narrow range. The transfer function modulates the weighted sum of the inputs whereby when input gets larger, output approaches unity but when input gets smaller, output approaches zero.

The model developed must be able to learn the relationship between a set of inputs and corresponding output when trained. Hence, the experimental data must be large, reliable and comprehensive enough to catch all essential aspects that might influence the input/output relationship within the practical range of all input parameters covered. Usually, the models are trained so that a particular set of inputs produces, as nearly as possible, a specific set of target outputs. In order to build an effective ANN model, the selection of database, network architecture and network training and testing are essential to conduct the modeling.

The accuracy of ANN predictions was evaluated using the mean absolute error (MAE) calculated by:

$$
M A E=\frac{1}{n} \sum_{i=1}^{n} \frac{\left|R_{\exp }-R_{\text {pred }}\right|}{R_{\text {pred }}} \times 100
$$

where $R_{e x} p$ is experimental value of SCC property from measured data, $R_{\text {pred }}$ is predicted value of SCC property by the neural network, and $\mathrm{n}$ is the number of data points.

\subsection{Database}

The ANN technique used in this study to model the fresh properties of SCC must be trained using a comprehensive number of representative experimental data sets in order to be become able to capture the relationships between the mix parameters of SCC and the measured fresh properties. The ANN was designed using 60 pairs of input and output vectors for slump flow, $\mathrm{T}_{50}, \mathrm{~T}_{60}, \mathrm{~V}$ funnel, Orimet, and L-box ratio predictions. The data sets are given in Table 3. The input vector consisted of mix variables and the output vectors were the slump flow $\mathrm{T}_{50}, \mathrm{~T}_{60}, \mathrm{~V}$-funnel, Orimet, and L-box ratio. For all predictions of the fresh properties of SCC, the input parameters were dosages of cement and limestone powder $\left(\mathrm{kg} / \mathrm{m}^{3}\right)$, water content, sand content $\left(\mathrm{kg} / \mathrm{m}^{3}\right)$, coarse aggregate content $\left(\mathrm{kg} / \mathrm{m}^{3}\right)$, dosage of superplasticizer $\left(\mathrm{kg} / \mathrm{m}^{3}\right)$ and the testing time $(\mathrm{min})$. 


\subsection{Slump flow test}

The neural network was trained to predict the slump flow values using a total of 60 patterns. Each training pattern contains an input vector of 7 elements representing the ingredients of concrete and time and a target representing the corresponding measured slump flow. Satisfactory completion of the training process was verified by calling the network model to predict the slump flow values of the concrete used in the training (40 data) sets and testing processes (20 data) sets and the responses were plotted in Fig. 5. It should be noted that the network has successfully learned to map between mix parameters and associated slump flow values, its performance in predicting the slump flow of the training mixes is satisfactory with an MAE $=3.3 \%$. The coefficient of correlation was very good (0.976).

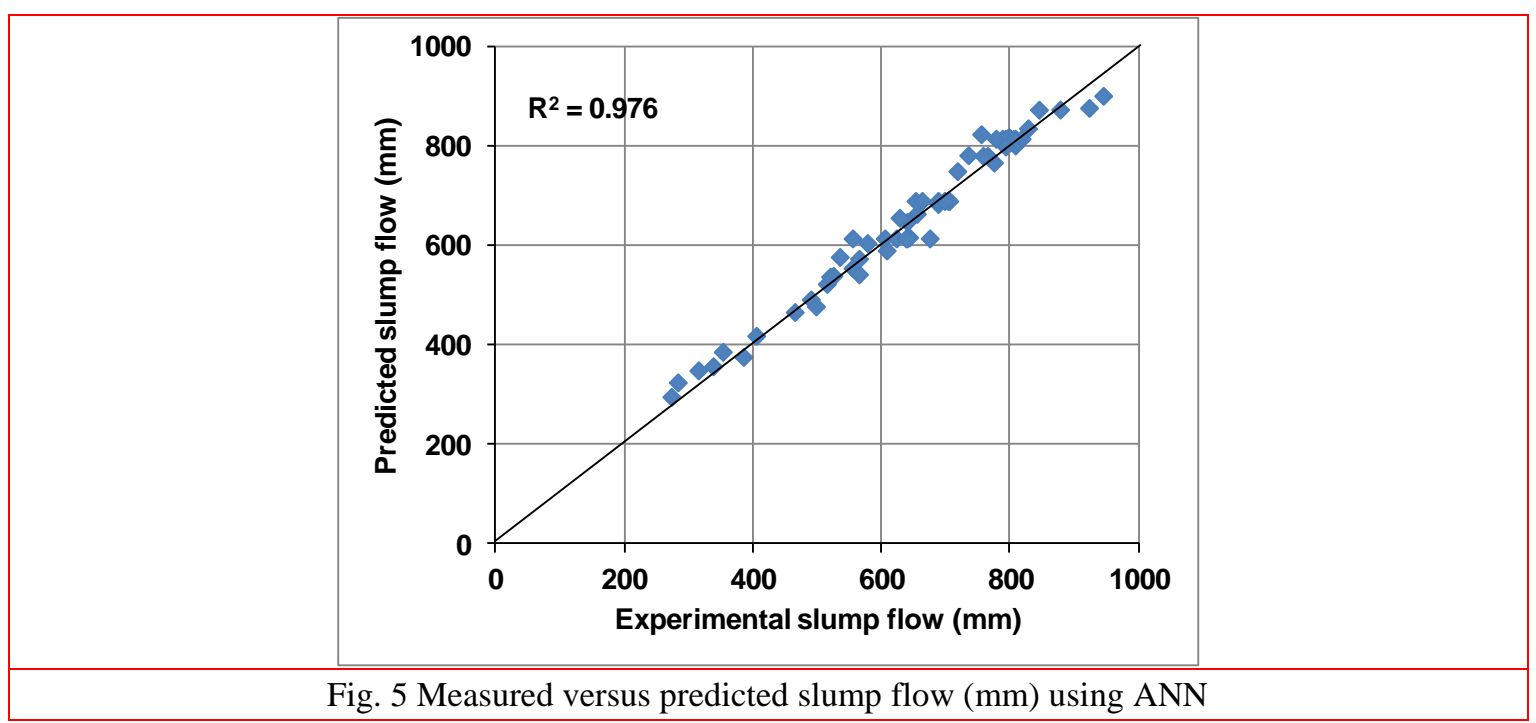

\section{$4.4 T_{50}$ and $T_{60}$}

Similarly, the same network architecture was applied using a total of 34 training patterns to predict $\mathrm{T}_{50}$ and $\mathrm{T}_{60}$ of SCC (18 for testing). The network was presented with training patterns containing the values of mix composition of concrete with time and the corresponding $\mathrm{T}_{50}$ and $\mathrm{T}_{60}$. Its task was to predict the $\mathrm{T}_{50}$ and $\mathrm{T}_{60}$ values for concrete used in the training process. The coefficients of correlation $\mathrm{R}^{2}$ for $\mathrm{T}_{50}$ and $\mathrm{T}_{60}$ were 0.957 and 0.823 , respectively (Figs. 6 and 7). With these data responses, the value of MAE were $13 \%$ and $16 \%$, respectively, and the model responses in predicting the $T_{50}$ and $T_{60}$ values of the training mixes were considered satisfactory. The slightly lower performance of the network model in this case is believed to be due to the numerically very small values of $\mathrm{T}_{50}$ and $\mathrm{T}_{60}$; even small prediction errors already lead to a high MAE and due to the higher variability in the experimental data itself which is also related to the difficulty of measure $\mathrm{T}_{50}$ and $\mathrm{T}_{60}$. 

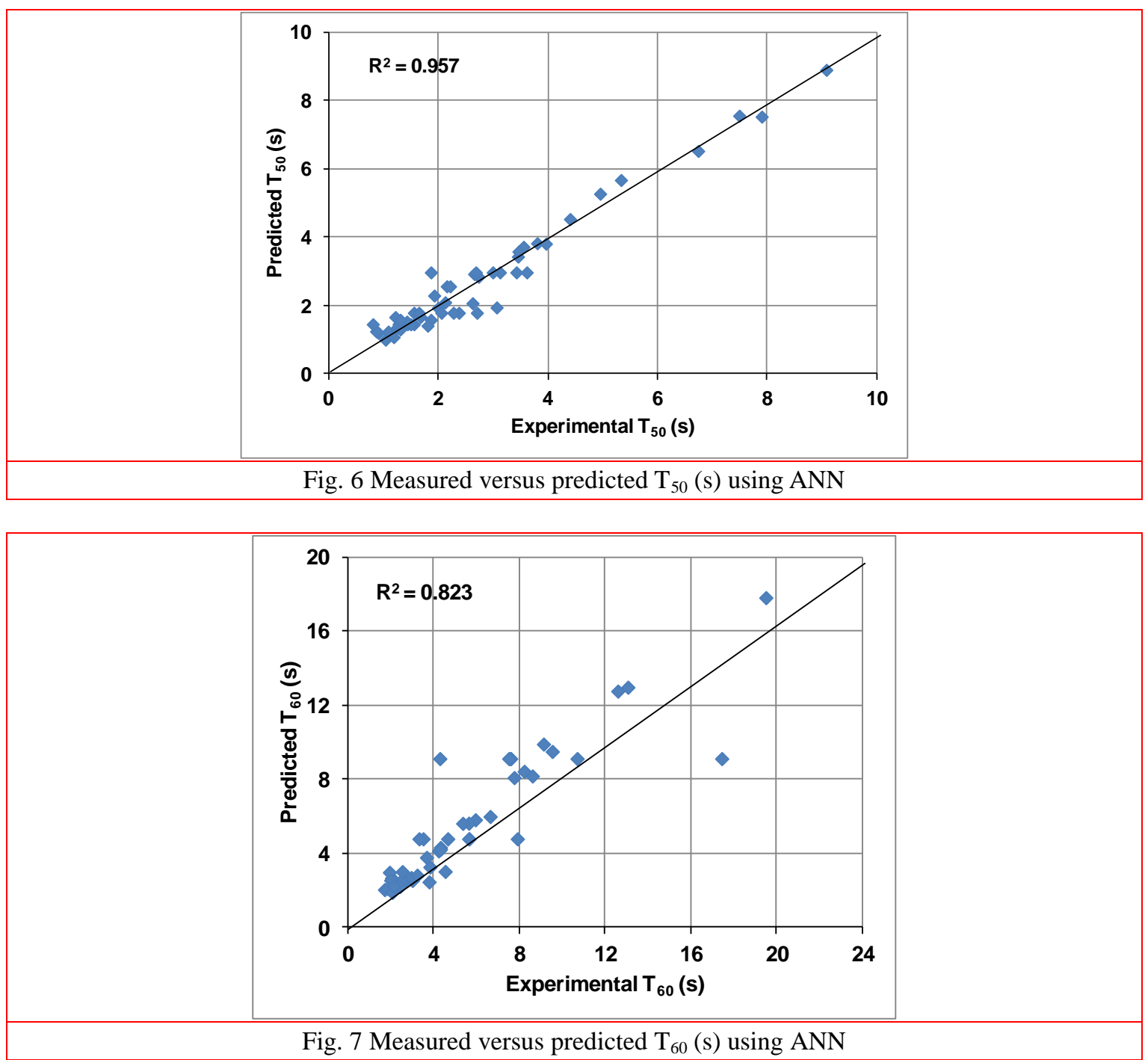

\subsection{V-funnel and Orimet tests}

The same ANN model was trained to predict the V-funnel and Orimet values using a total of 56 and 37 training patterns, respectively. After completion of the training process, the model was required to predict the V-funnel and Orimet values for the training mixes and its response. The coefficients of correlation $\mathrm{R}^{2}$ for $\mathrm{V}$-funnel and Orimet were 0.988 and 0.974 , respectively (Figs. 8 and 9). With data of V-funnel and Orimet of the training mixes, the values of MAE were $14 \%$ and $15 \%$, respectively. The slightly lower performance of the network model in this case is believed to be caused by the numerically very small values of V-funnel and Orimet times; small prediction errors cause a high MAE. It could also be due to the higher variability in the experimental data itself using V-funnel and Orimet tests, which are affected by all main flow characteristics of SCC and therefore, are more difficult to assess lab compared to slump flow values. 

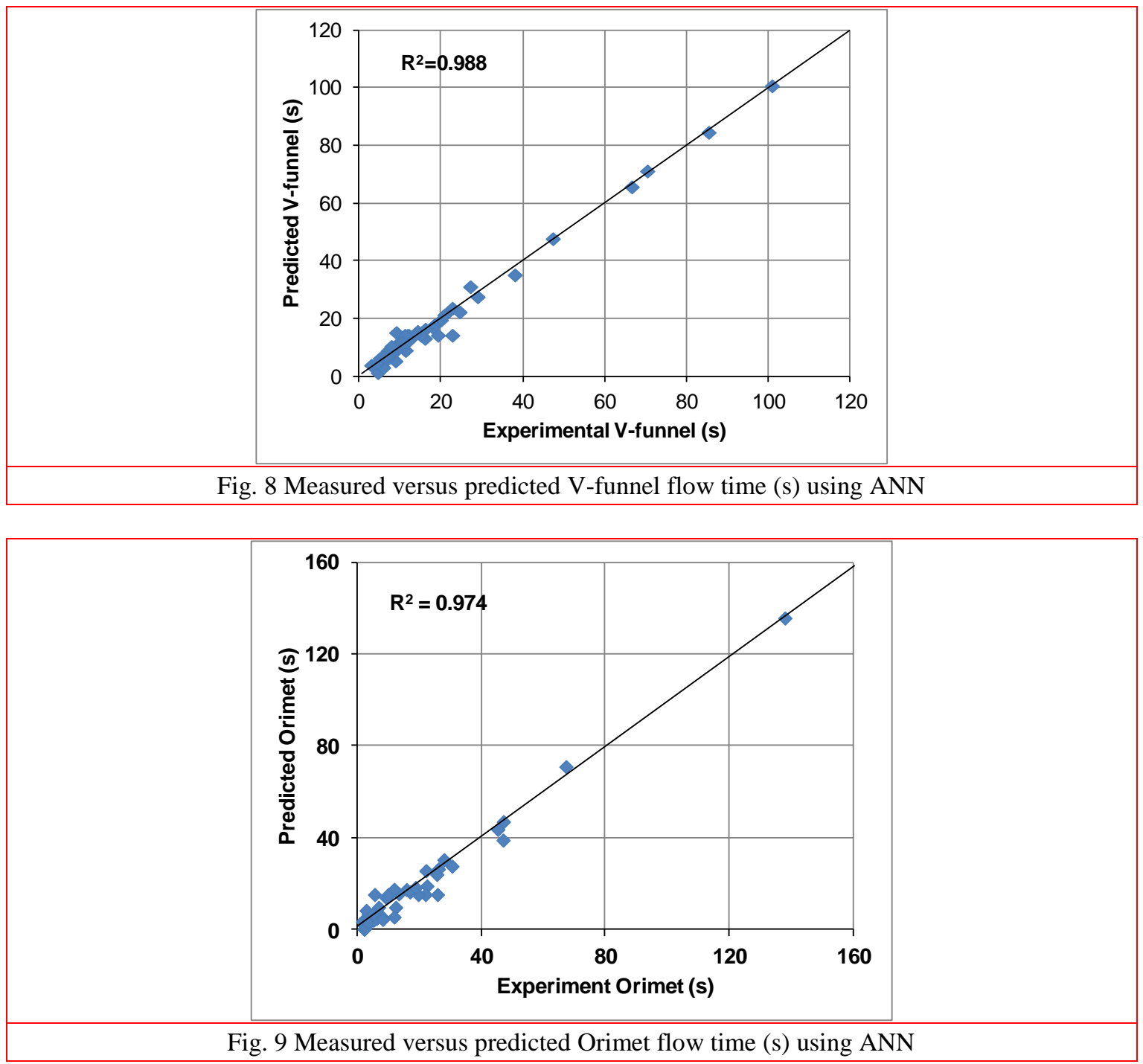

\subsection{L-box test}

A similar process was adopted in training the same neural network using a total of 60 and 40 training patterns to predict the L-box blocking ratio of SCC. The coefficient of correlation of $\mathrm{R}^{2}$ was 0.981 (Fig. 10) for the measured and predicted L-box ratios. The value of MAE was $22 \%$ for all results. The model response in predicting the L-box blocking ratio was considered satisfactory. 


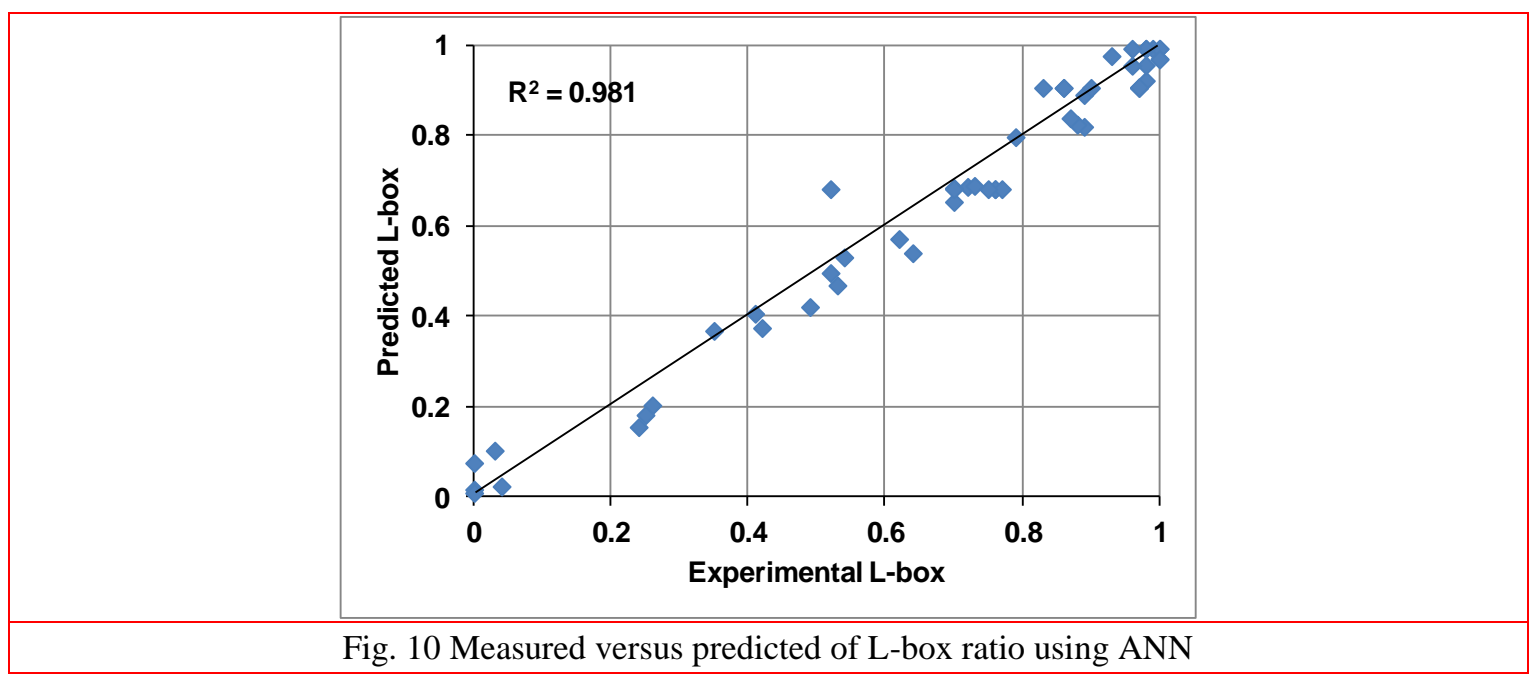

\subsection{Sensitivity of ANN models}

Since the ANN model developed herein showed satisfactory performance and demonstrated its ability to predict the fresh properties of SCC mixes designed within the practical range of the results, it would be worth investigating whether the model has captured the sensitivity of mix properties to individual mix composition parameters. Therefore, a single mix was randomly selected from the data and used to create six new mixes by changing the dosage of cement, or LSP, or water or SP, or sand, or coarse aggregate. The dosages of cement and LSP, water, SP, sand, and coarse aggregate were varied from 430 to $510 \mathrm{~kg} / \mathrm{m}^{3}, 120$ to $140 \mathrm{~kg} / \mathrm{m}^{3}, 180$ to $220 \mathrm{~kg} / \mathrm{m}^{3}, 3.5$ to $5.5 \mathrm{~kg} / \mathrm{m}^{3}, 600$ to $1000 \mathrm{~kg} / \mathrm{m}^{3}$, and 450 to $850 \mathrm{~kg} / \mathrm{m}^{3}$, respectively. The sensitivity of the effect time at 5 to $60 \mathrm{~min}$ on slump flow was also modelled. Fig. 11 shows the relationship between the dosage of cement, LSP, water, SP, sand, CA and time and the predicted values of slump flow. It is clear that increasing cement and LSP led to a reduction of the spread of slump flow due to the absorption of water by fine particles. As expected, the increase of water and SP and CA increased the slump flow. More water increases the flowability and increasing SP improved the dispersion of cement particles. However, the increase of sand led to a slight reduction of slump flow. The slump flow was smaller when it was measured at $30 \mathrm{~min}$ and $60 \mathrm{~min}$. 


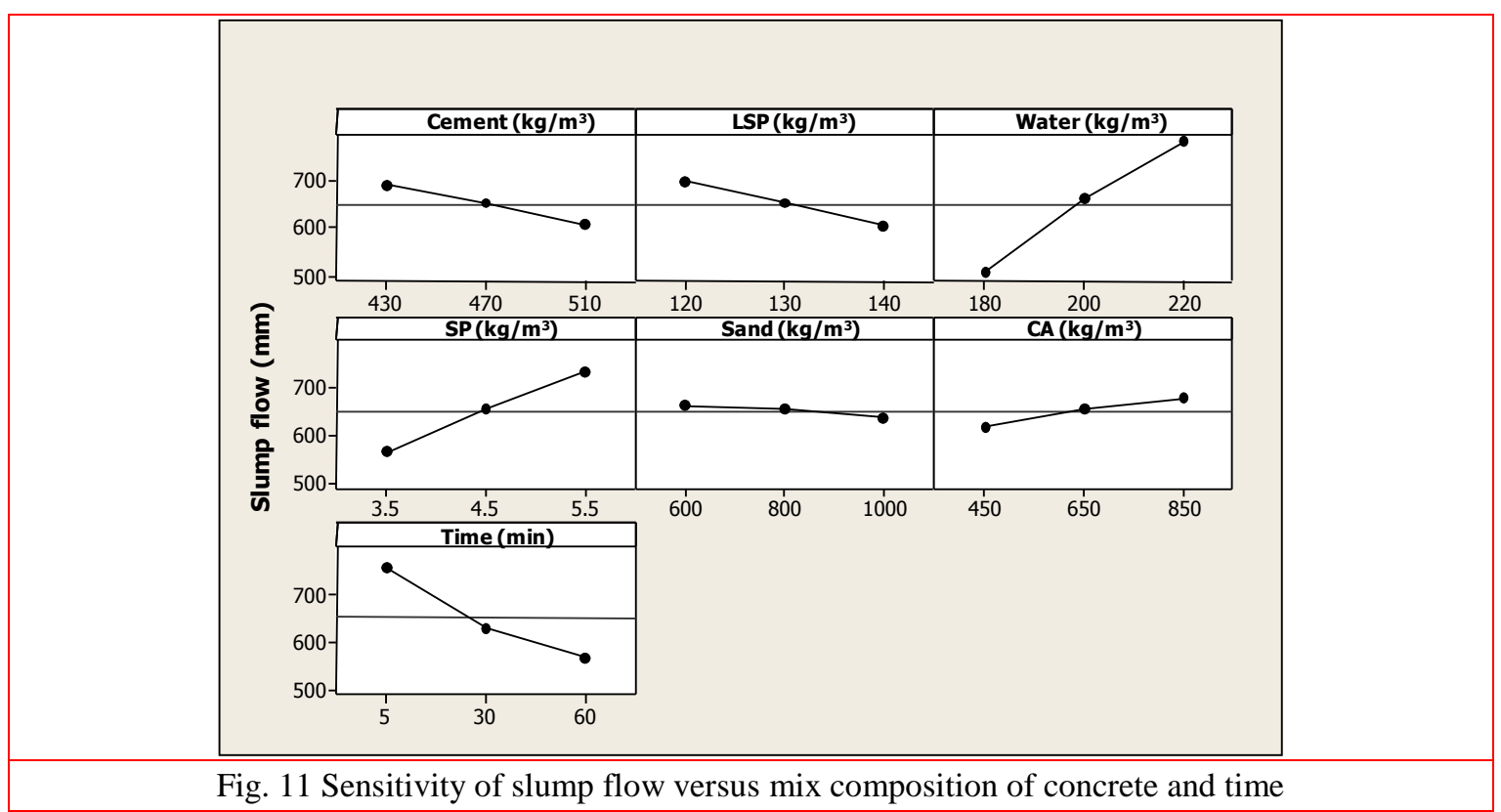

Similarly, new mixes were simulated from a single mix randomly selected from the testing data used in the $\mathrm{T}_{50}$ and $\mathrm{T}_{60}$ models, by changing the dosage of cement and LSP, water, SP, sand, and coarse aggregate to investigate the ability of the ANN model to recognize the influence of these parameters on the $T_{50}$ and $T_{60}$ values. Similar variation of the ingredients as for slump flow was used. Figs. 12 and 13 illustrate the ANN prediction of $T_{50}$ and $T_{60}$ values associated with different dosages of C, LSP, W, SP, sand, CA and time. As expected, it is indicated that by increasing the dosage of cement, LSP, the flowability reduced ( $\mathrm{T}_{50}$ and $\mathrm{T}_{60}$ increased). The increase of the dosage of water and $\mathrm{SP}$ on $\mathrm{T}_{50}$ and $\mathrm{T}_{60}$ caused an improvement of the filling ability of concrete. The effect of an increase of CA is more pronounced compared to variation of sand.

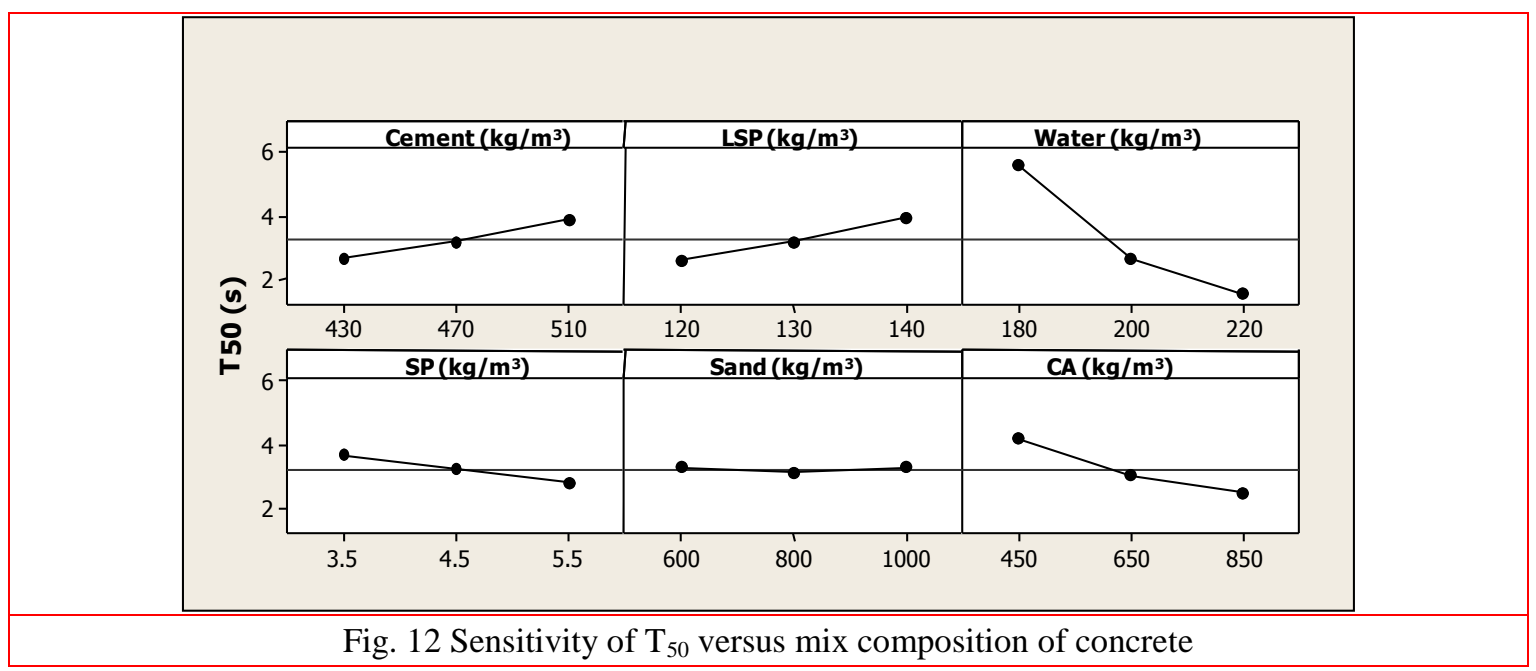




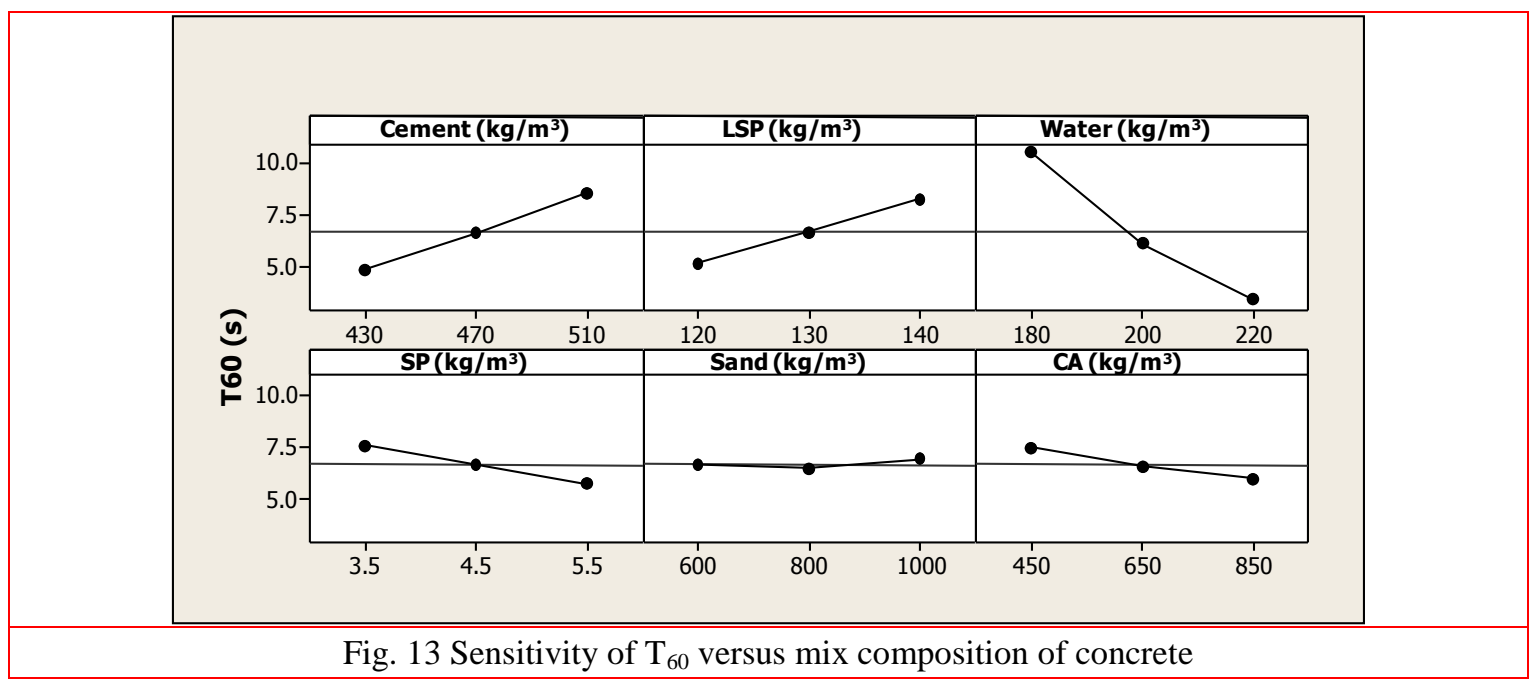

Figs. 14 and 15 present the predicted V-funnel and Orimet flow times obtained with ANN models for variations in mix composition. As expected, the dosage of cement, LSP and CA had a significant effect on the V-funnel and Orimet values. From these figures, as expected, it can be seen that the increase of dosages water and SP reduced the V-funnel and Orimet flow times leading to a better flowability and deformability. An increase of sand improved the V-funnel and Orimet values. Conversely, the CA increased these values which can be attributed to a lower passing ability. The flow times of V-funnel and Orimet increased at $60 \mathrm{~min}$ due to loss of flowability.

Other data sets were created from a single mix randomly selected for the L-box blocking ratio by using the ANN model to recognize the influence of cement, LSP, water, SP, sand, CA and time. Figure 16 illustrates the ANN prediction of L-box values. As expected, it is indicated that by increasing the dosages of cement and LSP led to a reduction of the L-box ratio. Conversely, the increase of water, SP, sand and CA demonstrated an increase of the L-box ratio which led to a better passing ability. It can be noticed from Fig. 16 that the L-box ratio reduced with the time. 


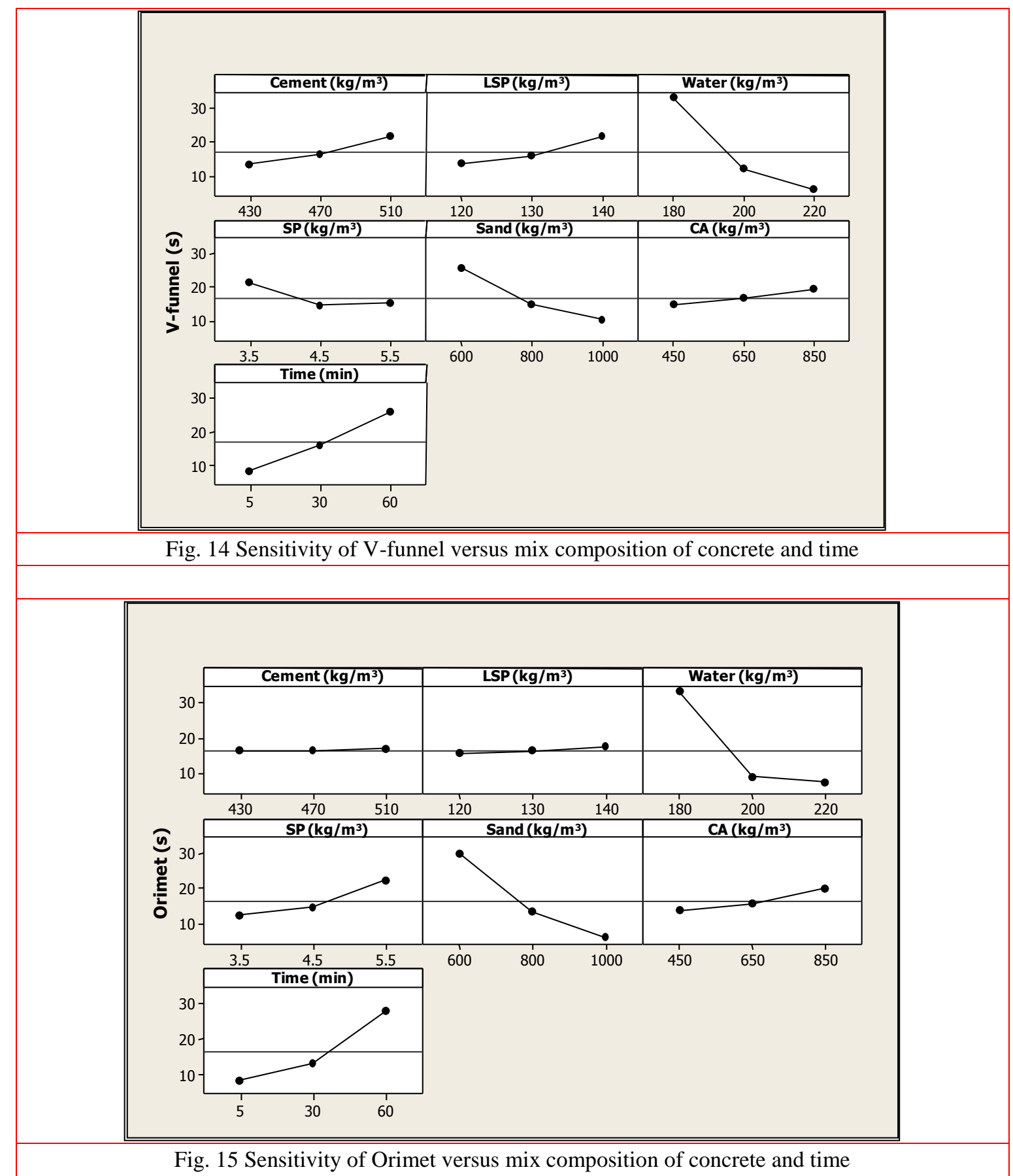




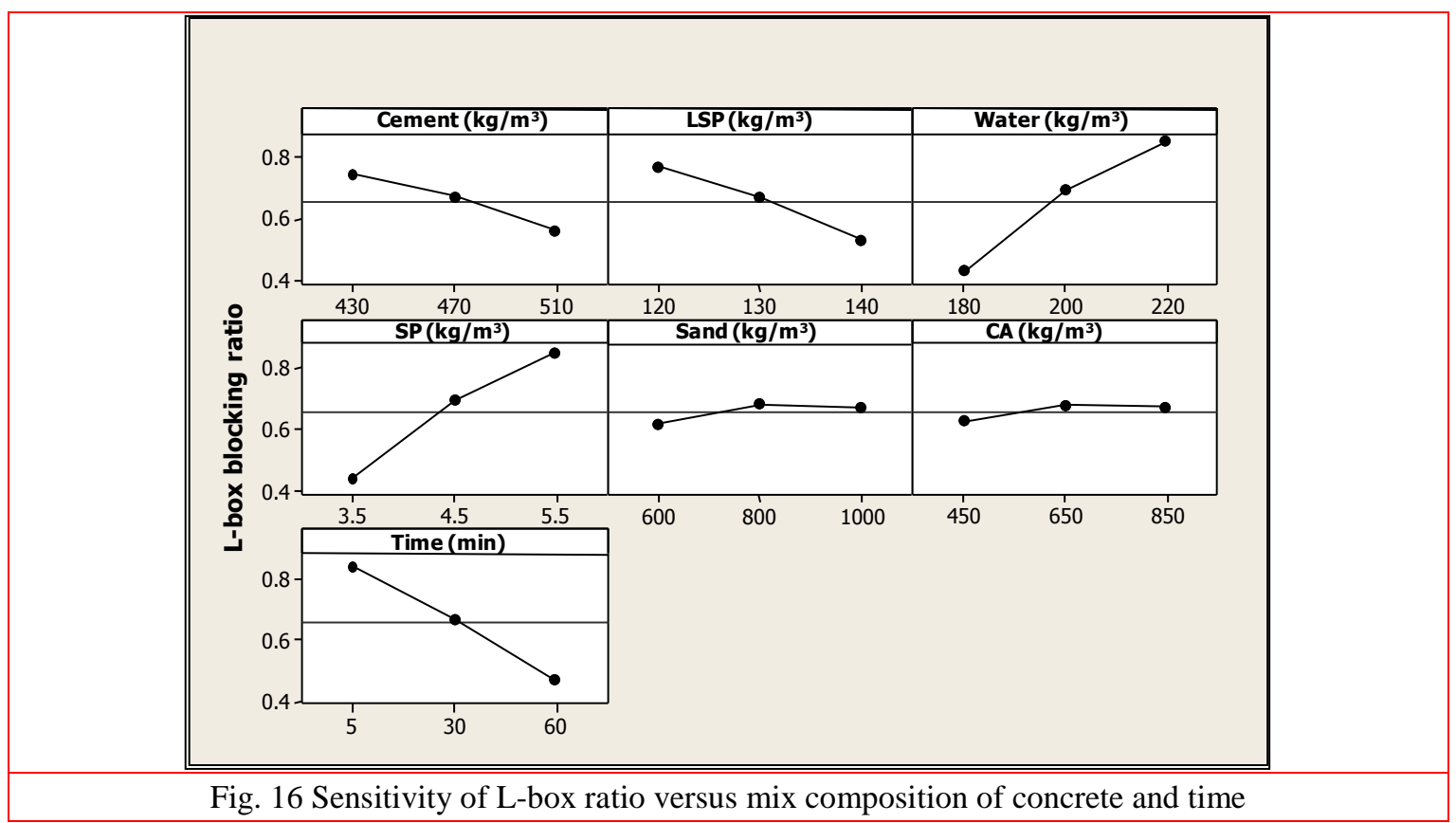

\section{Conclusions}

This study presented that the artificial neural network (ANN) modelling can be used to predict the fresh properties of self-compacting concrete. Input parameters were the mix composition namely the cement content, the dosages of limestone powder, water, fine aggregate, coarse aggregate, and superplasticizer and time. Based on this investigation, the following conclusions can be warranted:

1- This study demonstrates the feasibility of using an artificial neural network to predict the fresh properties of SCC such as filling ability, flowability and passing ability with good accuracy. The ANN model thus developed was not only able to predict the fresh properties of mixes used in the training process, but it also generalized its predictions beyond the training data to new mixes designed within the practical training range.

2- The prediction of the fresh properties of SCC (slump flow, $\mathrm{T}_{50}$ and $\mathrm{T}_{60}$, V-funnel, Orimet and L-box blocking ratio) as a function of mix ingredients is difficult to achieve analytically, whereas a successfully trained neural network model can predict such behavior instantly and accurately. Therefore, the use of ANNs are a powerful alternative approach to the available traditional statistical methods in modeling the fresh properties of SCC.

3- The ANN model developed in this study demonstrated the ability to recognize and evaluate the effect of mix composition on slump flow, $\mathrm{T}_{50}$ and $\mathrm{T}_{60}$, V-funnel, Orimet and L-box blocking ratio. The sensitivity analysis showed that the developed models for slump flow, $\mathrm{T}_{50}$ and $\mathrm{T}_{60}$, V-funnel, Orimet and L-box blocking ratio captured the effect of mix composition ingredients and the time of testing on the results. Thus, it could be used to simulate mixes with tailor-made properties without the need to execute a large number of trial batches as it is current practice. 
4- The outcomes of this study are very promising. Further enhancement of the ANN model can be achieved by using new data on fresh properties which can easily be used for a wider range of input variables by providing additional training sets.

\section{Acknowledgments}

The authors wish to thank the European Union which supported this Growth Project entitled: "Testing SCC" Contract GRD2-2000-30024 with 12 partners from Europe: University of Paisley (UK), University College London (UK), John Doyle Construction (UK), Delft University of Technology (The Netherlands), Ghent University (Belgium), University of Stuttgart (Germany), GTM Construction (France), Swedish Cement and Concrete Research Institute- CBI (Sweden), Swedish National Testing and Research Institute (Sweden), Betongindustri (Sweden), Dansk Beton Teknik (Denmark), and The Icelandic Building Research institute (IBRI) (Iceland).

\section{References}

American Concrete Institute ACI 237R-07 (2007) "Self-consolidating concrete", ACI Committee 237, Emerging Technology Series, American Concrete Institute, Farmington Hills, 30p.

Bartos, P.J.M., Sonebi, M., Tamimi, A.K. (2002) "Workability and rheology of fresh concrete: Compendium of tests," Report of RILEM Technical Committee TC 145-WSM: Workability of Special Concrete Mixes, RILEM Publications S.A.R.L, Paris, 127 p..

Çevik, A. "A New Approach for Elastoplastic Analysis of Structures: Neural Networks", PhD Thesis, University of Gaziantep, Turkey, $227 \mathrm{p}$.

De Schutter, G. and Audenaert, K. (2007) "Durability of self-compacting concrete", RILEM Report 38, RILEM Publications, Paris, Sept. 2007, 208p.

Duan, Z.H., Kou, S.C., Poon, C.S. (2013) "Prediction of compressive strength of recycl ed concrete using artificial neural networks, Construction and Building Materials, 40, 1200 $-1206$.

EFNARC (2002). "Specification and Guidelines for Self-Compacting Concrete", The European federation dedicated to specialist construction chemicals and concrete systems, EFNARC, Norfolk $\mathrm{UK}, 32 \mathrm{p}$.

El-Chabib, H., Nehdi, M., and Sonebi, M. (2003) "Artificial intelligence model for flowable concrete mixtures used in underwater construction and repair," ACI Materials Journal, 100(2), 165-173.

EN 197-1:2001. Cement, Part 1: Composition, specifications and conformity criteria for common cements. 2001.

Haykin, S. (1999) "Neural Networks: A Comprehensive Foundation," Prentice Hall, 2nd Edition, Upper Saddle River, N.J.

Hossain, KMA., Lachemi, M., Sammour, M., Sonebi, M. (2012) "Influence of polyvinyl alcohol, steel and hybrid fibers on fresh and rheological properties of self-consolidating concrete", ASCE Materials Journal in Civil Engineering, 24(9), 1211-1220.

Khatib, J.M. (2008) "Performance of self-compacting concrete containing fly ash", Construction Building Materials, 22(9), 1963-1971.

Leemann, A., Winnefeld, F. (2007) "The effect of viscosity modifying agents on mortar and 
concrete", Cement and Concrete Composites, 29, 341-349.

Mazloom, M., Yoosefi, M.M. (2013) "Predicting the indirect tensile strength of self-compacting concrete using artificial neural networks", Computers and Concrete, 12(3), 285-301.

Mohebbi, A., Shekarchi, M., Mahoutian, M., Mohebbi, S. (2011) "Modeling the effects of additives on rheological properties of fresh self-consolidating cement paste using artificial neural network", Computers and Concrete, 18(3), 279-292.

Prasad, B.K.R., Eskandari, H., Reddy, B.V.V. (2009) "Prediction of compressive strength of SCC and HPC with high volume fly ash using ANN," Construction and Building Materials, 23, $117-128$.

Sonebi, M., Tamimi, A., and Bartos, P.J.M. (2003) "Performance and cracking behaviour of reinforced beams cast with self-compacting concrete," ACI Materials Journal, 100(6), 492-500.

Sonebi, M. (2004) "Medium strength self-compacting concrete containing fly ash : modelling using factorial experimental plans", Cement and Concrete Research, 34(7), 1199-1208.Sonebi, M., Nanukuttan, S. (2009a) "Transport properties of self-consolidating concrete", ACI Materials Journal, 106(2), 161-166.

Sonebi M., Cevik A. (2009b) "Prediction of fresh and hardened properties of self-consolidating concrete using neurofuzzy approach", Journal of Materials in Civil Engineering, 21(11), 672-679.

Sonebi, M., Malinov, S. (2011) "Neural network modeling of rheological parameters of grouts containing viscosity modifying agent”, ACI Materials Journal, 108(3), 316-326

Tabatabaei, R., Sanjari, H.R., Shamsadini, M. (2014) "The use of artificial neural networks in predicting ASR of concrete containing nano-silica", Computers and Concrete, 13(6), 739-748.

Yeh, I.C. (2007) "Modeling slump flow of concrete using second-order regressions and artificial neural networks," Cement \& Concrete Composites, 29, 474-480. 